\title{
Continuous-flow ventricular assist device exchange is safe and effective in prolonging support time in patients with end-stage heart failure
}

Jatin Anand, MD, ${ }^{a}$ Steve K. Singh, MD, MSc, ${ }^{a}$ Rubén Hernández, MD, ${ }^{b}$ Steven M. Parnis, BS, ${ }^{b}$ Andrew B. Civitello, MD, ${ }^{\mathrm{a}, \mathrm{b}}$ William E. Cohn, MD, ${ }^{\mathrm{a}, \mathrm{b}}$ and Hari R. Mallidi, MD ${ }^{\mathrm{a}, \mathrm{b}}$

Objective: Although the development of continuous-flow ventricular assist devices (CF-VAD) has improved the reliability of these devices, VAD exchange is still occasionally necessary. The focus of this study was to analyze our institution's entire experience with primary CF-VAD implants, evaluate the baseline variables, determine which factors predict the need for exchange, and evaluate the impact of exchange on survival and event-free survival.

Methods: We retrospectively reviewed the data of all patients in a single center who received a primary CF-VAD implant between December 1999 and December 2013. All CF-VAD exchanges were reviewed; demographics, indications, preoperative and operative data, and clinical outcomes were summarized. Univariate and multivariable regression analyses were performed to ascertain predictors for exchange. Time-to-event and survival analyses were also performed.

Results: We identified 469 patients who underwent 546 CF-VAD implantations. Of these patients, 66 (14\%) underwent 77 exchanges from one CF-VAD to another. The primary indications included hemolysis or thrombosis $(n=49 ; 63.6 \%)$, infection $(n=9 ; 11.7 \%)$, or other causes $(n=19 ; 24.7 \%)$. Survival was not significantly different between the exchange and nonexchange groups. Multivariable regression analysis identified a history of cerebrovascular events as a significant predictor for exchange. Among exchange patients, 11 underwent heart transplantation, 3 had their CF-VADs explanted, 26 had ongoing support, and 26 died during device support.

Conclusions: In our series of contemporary CF-VAD exchanges, a history of previous cerebrovascular events was a significant predictor for exchange. Exchange did not affect early or late survival. Our data suggest that aggressive surgical treatment of pump-related complications with exchange is safe and justified. (J Thorac Cardiovasc Surg 2015;149:267-78)

See related commentary on pages $279-80$.

Supplemental material is available online.

From the Division of Transplant and Assist Devices, ${ }^{\text {a }}$ Department of Surgery, Baylor College of Medicine; and Center for Cardiac Support, ${ }^{\mathrm{b}}$ Texas Heart Institute, Houston, Tex.

Disclosures: Authors have nothing to disclose with regard to commercial support. Read at the 40th Annual Meeting of The Western Thoracic Surgical Association, Dana Point, California, June 25-28, 2014.

J.A. and S.K.S. contributed equally toward the study and the manuscript.

Received for publication June 25, 2014; revisions received July 28, 2014; accepted for publication Aug 7, 2014; available ahead of print Oct 11, 2014.

Address for reprints: Hari R. Mallidi, MD, Division of Transplant and Assist Devices, Department of Surgery, Baylor College of Medicine, Texas Heart Institute, 6770 Bertner Ave, C-355, Houston, TX 77030 (E-mail: mallidi@bcm.edu) $0022-5223 / \$ 36.00$

Copyright $\odot 2015$ by The American Association for Thoracic Surgery http://dx.doi.org/10.1016/j.jtcvs.2014.08.054
The use of continuous-flow ventricular assist devices (CF-VADs) has had a major impact on our ability to successfully treat end-stage cardiac disease. CF-VADs can be used as a bridge to transplantation, a bridge to recovery, or as destination therapy with meaningful clinical results. ${ }^{1-8}$

Over the past decade, mechanical circulatory support (MCS) devices have supported thousands of patients with excellent overall outcomes, ${ }^{5}$ particularly compared with medical therapy alone. ${ }^{9}$ The experience with this technology continues to rapidly expand; more than 12,000 patients have been enrolled in the Interagency Registry for Mechanically Assisted Circulatory Support (INTERMACS) since 2006 in the United States alone.

In comparison with first-generation devices, CF-VADs perform with remarkably improved durability and overall clinical outcomes. ${ }^{10,11}$ However, adverse events, such as hemolysis, bleeding, thrombosis, infection, stroke, and mechanical failure, continue to be important and potentially devastating problems associated with this therapy. ${ }^{5,12-15}$ When the adverse event is associated with a pump-related 


$\begin{array}{ll}\text { Abbreviations and Acronyms } \\ \text { CI } & \text { confidence interval } \\ \text { CF-VAD } & \text { continuous-flow ventricular assist } \\ & \text { device } \\ \text { CPB } & =\text { cardiopulmonary bypass } \\ \text { INTERMACS = } & \text { Interagency Registry for } \\ & \text { Mechanically Assisted Circulatory } \\ & \text { Support } \\ \text { MCS } & =\text { nechanical circulatory support } \\ \text { OR } & =\text { odds ratio } \\ \text { SD } & =\text { standard deviation } \\ \text { VAD } & =\text { ventricular assist device }\end{array}$

problem, it can often be managed by expeditious device exchange. Several groups, including our own, have demonstrated that judicious device exchange can potentially overcome some of the catastrophic consequences of such ventricular assist device (VAD)-related adverse events. ${ }^{16-24}$ The focus of this study was to analyze our institution's entire large experience with primary CF-VAD implants; to evaluate the baseline variables; and to determine which factors predict the need for exchange and the impact of exchange on survival and event-free survival.

\section{METHODS}

\section{Study Cohort}

Institutional Review Board approval with appropriate informed consent was obtained to perform a retrospective review of our center's patient database. All patients implanted with any CF-VAD between December 1999 and December 2013 were identified. Within this population, we identified those patients who underwent 1 or more VAD exchanges. Our aim was to compare the cohort of patients with VAD exchange with the cohort without exchange within the overall population of contemporary CF-VAD recipients. Any patient who had received a durable, non-CF-VAD at any point during their clinical course was excluded from this analysis.

\section{Primary End Points}

Demographics, indications, echocardiographic and hemodynamic parameters, operative, perioperative, and late clinical outcomes data were reviewed and summarized. Our primary aim was to determine significant independent predictors for VAD exchange. Secondary end points were overall survival and event-free survival while on VAD support and to the date of last follow-up. Event-free survival was defined as freedom from death, transplant, or VAD explant. The significance of VAD exchange as an independent predictor of survival was also evaluated.

\section{Statistical Analysis}

Demographics, indications for support, operative data, and clinical outcomes were compared between the CF-VAD exchange and nonexchange cohorts. Continuous variables were analyzed with the 2 -sample $t$ test, and categorical variables with the $\chi^{2}$ or Fisher exact test. Means are presented with standard deviations.

Our primary aim of ascertaining predictors of VAD exchange was achieved using multivariable logistic regression modeling. We included all univariate variables that differed between the 2 cohorts $(P<.05$, or $P<.1$ trend), as well as all clinically relevant variables of interest. We did not include multiple correlated variables. Stepwise regression was performed eliminating all variables with $P>.1$. The result was a parsimonious clinically relevant model. This was performed for VAD exchange as the outcome variable, and repeated for overall survival and survival while on VAD support as the outcome, with VAD exchange remaining in the predictor model.

Time-to-event survival analysis was performed creating Kaplan-Meier curves. Both the log-rank and the Wilcoxon tests were used to compare differences between the cohorts.

Late follow-up was complete for $95 \%$ of patients for a mean time period of $2.1 \pm 2.4$ years (maximum, 13.3 years). There was minimal missing data $(<5 \%)$ for all variables and/or data points. For all analyses, $P$ values were 2-sided. Analyses were conducted with the R statistical software (Vienna, Austria).

\section{RESULTS \\ Patient Characteristics}

During our study period (December 1999 to December 2013), 469 patients underwent 546 CF-VAD implantations. Initially implanted pumps included the HeartMate II (Thoratec, Inc Pleasanton, Calif; $n=327$ ), the Jarvik 2000 (Jarvik Heart Inc, New York, NY; $n=74)$, the HeartWare HVAD (HeartWare, Inc, Miami Lakes, Fla; $\mathrm{n}=65$ ), the DuraHeart (Terumo Heart, Inc, Ann Arbor, Mich; $n=2$ ), and the MicroMed DeBakey (MicroMed Inc, Houston, Tex; $n=1$ ). Of these patients, 66 underwent 77 VAD exchanges from their existing device to another CF-VAD; a $14 \%$ exchange incidence. The exchanged devices included the HeartMate II $(\mathrm{n}=59)$, the Jarvik $2000(\mathrm{n}=10)$, and the HeartWare HVAD $(n=8)$ devices. These devices were exchanged for the HeartMate II $(\mathrm{n}=52)$, the Jarvik $2000(\mathrm{n}=10)$, and the HeartWare HVAD $(\mathrm{n}=15)$ devices. Total exchange rates for each device were 0.13 events per patient-year $(15.5 \%)$ for the HeartMate II, 0.29 events per patient-year $(11.9 \%)$ for the Jarvik 2000, and 0.16 events per patientyear $(10 \%)$ for the HeartWare HVAD.

Table 1 lists the baseline device, demographic, clinical, echocardiographic, and invasive hemodynamic data, and the operative and postoperative outcomes of the $\mathrm{CF}$ VAD exchange cohort $(n=66$ patients) and compares them with the corresponding data from the nonexchange cohort ( $n=403$ patients). There was a similar proportion of bridge to transplantation versus destination therapy indications in both groups. The group with 1 or more VAD exchanges had statistically longer duration of VAD support, more preoperative cerebrovascular events, higher platelet count and albumin levels, less INTERMACS class 1 status, and less frequently used preoperative temporary MCS (eg, Impella, Tandem Heart, intra-aortic balloon pump, and/or extracorporeal membrane oxygenation [ECMO]).

\section{Exchange Cohort}

Table 2 summarizes the characteristics of the 66 patients who underwent 1 or more VAD exchanges and the rates of exchange by device. Hemolysis/suspected thrombosis was the primary indication (64\%). Surgical 
TABLE 1. Univariate analysis of baseline factors for nonexchange and exchange cohorts

\begin{tabular}{|c|c|c|c|c|}
\hline & Total $(n=469)$ & Nonexchange $(n=403)$ & Exchange $(n=66)$ & $P$ value \\
\hline Device type, n (\%) & & & & .8 \\
\hline Jarvik 2000 & $74(15.8)$ & $64(15.9)$ & $10(15.1)$ & \\
\hline HeartMate II & $327(69.7)$ & $278(69)$ & $49(74.2)$ & \\
\hline HeartWare HVAD & $65(13.9)$ & $58(14.4)$ & $7(10.6)$ & \\
\hline DuraHeart & $2(0.4)$ & $2(0.5)$ & 0 & \\
\hline MicroMed DeBakey & $1(0.2)$ & $1(0.2)$ & 0 & \\
\hline Age, $y \pm S D$ & $54.2 \pm 13.9$ & $54.4 \pm 14$ & $51.3 \pm 15.8$ & .2 \\
\hline Gender, $\mathrm{n}(\%)$ & & & & .07 \\
\hline Male & $357(76.1)$ & $313(77.7)$ & $44(66.7)$ & \\
\hline Female & $112(23.9)$ & $90(22.3)$ & $22(33.3)$ & \\
\hline Race, n (\%) & & & & .8 \\
\hline Native American & $3(0.6)$ & $3(0.7)$ & 0 & \\
\hline Asian & $10(2.1)$ & $9(2.2)$ & $1(1.5)$ & \\
\hline African American & $120(25.6)$ & $99(24.6)$ & $21(31.8)$ & \\
\hline White & $256(54.6)$ & $222(55.1)$ & $34(51.5)$ & \\
\hline Hispanic & $58(12.4)$ & $50(12.4)$ & $8(12.1)$ & \\
\hline Unknown/other & $22(4.7)$ & $20(5)$ & $2(3)$ & \\
\hline Device strategy, n (\%) & & & & .8 \\
\hline Bridge to transplantation & $286(61)$ & $247(61.3)$ & $39(59.1)$ & \\
\hline Destination therapy & $183(39)$ & $156(38.7)$ & $27(40.9)$ & \\
\hline Cause of heart failure, $\mathrm{n}(\%)$ & & & & .1 \\
\hline Nonischemic cardiomyopathy & $274(58.4)$ & $229(56.8)$ & $45(68.2)$ & \\
\hline Ischemic cardiomyopathy & 195 (41.6) & $174(43.2)$ & $21(31.8)$ & \\
\hline Duration of support, $d \pm S D$ & $462.6 \pm 502.4$ & $421.4 \pm 481.2$ & $714.5 \pm 556.7$ & $<.001$ \\
\hline Body mass index, $\mathrm{kg} / \mathrm{m}^{2} \pm \mathrm{SD}$ & $27.7 \pm 6.3$ & $27.6 \pm 6.3$ & $28.4 \pm 6.2$ & .3 \\
\hline Body surface area, $\mathrm{m}^{2} \pm \mathrm{SD}$ & $2 \pm 0.3$ & $2.0 \pm 0.3$ & $2.0 \pm 0.3$ & .3 \\
\hline \multicolumn{5}{|l|}{ Comorbidities, n (\%) } \\
\hline Diabetes & $193(41.2)$ & $169(41.9)$ & $24(36.4)$ & .5 \\
\hline Hypertension & $223(47.9)$ & $192(48)$ & $31(47)$ & 1.0 \\
\hline Chronic obstructive pulmonary disease & $58(12.4)$ & $48(11.9)$ & $10(15.4)$ & 6 \\
\hline Stroke or transient ischemic attack & $49(10.9)$ & $34(8.8)$ & $15(23)$ & .001 \\
\hline Renal replacement therapy & $29(6.2)$ & $29(7.2)$ & 0 & .05 \\
\hline Chronic kidney disease & $184(39.3)$ & $159(39.5)$ & $25(37.9)$ & .9 \\
\hline Respiratory failure & $68(14.5)$ & $61(15.2)$ & 7 (10.6) & .4 \\
\hline Hypercoaguable state & $14(3)$ & $10(2.5)$ & $4(6.1)$ & .2 \\
\hline Deep venous thrombosis & $26(5.5)$ & $23(88.5)$ & $3(11.5)$ & .9 \\
\hline Pulmonary embolism & $22(4.7)$ & $17(4.2)$ & $5(7.6)$ & .4 \\
\hline Previous cardiac surgery & $170(36.2)$ & $152(37.7)$ & $18(27.3)$ & .1 \\
\hline Ventricular arrhythmia & $156(33.3)$ & $131(32.5)$ & $25(37.9)$ & .5 \\
\hline Atrial fibrillation & $130(27.7)$ & $113(28)$ & $17(25.8)$ & .8 \\
\hline Anticoagulation & $151(34.5)$ & $134(35.8)$ & $17(26.6)$ & .2 \\
\hline Antiplatelet therapy & $206(47.1)$ & $181(48.5)$ & $25(39.1)$ & .2 \\
\hline Intracardiac thrombus & $36(7.8)$ & $31(7.8)$ & $5(7.6)$ & 1.0 \\
\hline Infection & $52(11.2)$ & $44(11)$ & $8(12.1)$ & 1.0 \\
\hline Endocarditis & $3(0.6)$ & $3(0.7)$ & 0 & 1.0 \\
\hline Active immunosuppression & $21(4.5)$ & $15(3.8)$ & $6(9.1)$ & .1 \\
\hline Tobacco use history & $195(42.1)$ & $172(43.3)$ & $23(34.8)$ & .2 \\
\hline \multicolumn{5}{|l|}{ Laboratory results } \\
\hline Hemoglobin $(\mathrm{g} / \mathrm{dL})$ & $11.6 \pm 2.1$ & $11.6 \pm 2.1$ & $11.9 \pm 2.2$ & .1 \\
\hline Leukocytes $(\mathrm{K} / \mu \mathrm{L})$ & $9.34 \pm .3$ & $9.4 \pm 4.4$ & $8.4 \pm 3.2$ & .1 \\
\hline Platelets $(\mathrm{K} / \mu \mathrm{L})$ & $206 \pm 87.4$ & $203.3 \pm 88.2$ & $222 \pm 81.1$ & .04 \\
\hline Sodium $(\mathrm{mEq} / \mathrm{L})$ & $135.1 \pm 4.7$ & $135.1 \pm 4.6$ & $135.1 \pm 5.1$ & .9 \\
\hline Creatinine (mg/dL) & $1.4 \pm 0.7$ & $1.4 \pm 0.7$ & $1.4 \pm 0.6$ & 1.0 \\
\hline Blood urea nitrogen $(\mathrm{mg} / \mathrm{dL})$ & $31.4 \pm 18.9$ & $31.8 \pm 19.1$ & $28.7 \pm 17.7$ & .2 \\
\hline Aspartate aminotransferase (U/L) & $73.4 \pm 173.9$ & $77.3 \pm 186.6$ & $49.4 \pm 44.3$ & .4 \\
\hline
\end{tabular}




\begin{tabular}{|c|c|c|c|c|}
\hline & Total $(n=469)$ & Nonexchange $(n=403)$ & Exchange $(n=66)$ & $P$ value \\
\hline Alanine aminotransferase (U/L) & $79.8 \pm 169.9$ & $85.5 \pm 181.7$ & $45.5 \pm 51$ & .1 \\
\hline Alkaline phosphatase (U/L) & $103.9 \pm 56.9$ & $105.1 \pm 56.6$ & $97.5 \pm 58.4$ & .2 \\
\hline Total bilirubin (mg/dL) & $2.0 \pm 3.7$ & $2.1 \pm 3.9$ & $1.4 \pm 1.6$ & .1 \\
\hline Albumin (g/dL) & $3.7 \pm 1.4$ & $3.6 \pm 1.4$ & $3.9 \pm 0.9$ & .01 \\
\hline Prealbumin (mg/dL) & $18.1 \pm 8.2$ & $17.9 \pm 8.1$ & $19 \pm 8.5$ & .7 \\
\hline Prothrombin time (s) & $13.3 \pm 5.5$ & $13.4 \pm 5.8$ & $12.7 \pm 3.8$ & .2 \\
\hline International normalized ratio & $1.2 \pm 0.4$ & $1.2 \pm 0.4$ & $1.2 \pm 0.4$ & .5 \\
\hline Activated partial thromboplastin time (s) & $40.4 \pm 22.3$ & $40.5 \pm 22.1$ & $40.3 \pm 22.9$ & .7 \\
\hline Lactate dehydrogenase (U/L) & $338.1 \pm 205.1$ & $342 \pm 210.5$ & $315.1 \pm 169.1$ & .1 \\
\hline Brain natriuretic peptide $(\mathrm{pg} / \mathrm{mL})$ & $1155 \pm 1127$ & $1169.3 \pm 1121.4$ & $1083.2 \pm 1165.7$ & .5 \\
\hline \multicolumn{5}{|l|}{ Echocardiogram, n (\%) } \\
\hline Left ventricular ejection fraction & & & & .7 \\
\hline$<20 \%$ & $281(61.4)$ & $241(61.3)$ & $40(61.5)$ & \\
\hline $20 \%-29 \%$ & $148(32.3)$ & $125(31.8)$ & $23(35.4)$ & \\
\hline $30 \%-39 \%$ & $27(5.9)$ & $25(6.4)$ & $2(3)$ & \\
\hline $40 \%-49 \%$ & $2(0.4)$ & $2(0.5)$ & 0 & \\
\hline Left ventricular internal diastolic dimension & $6.7 \pm 1.1$ & $6.6 \pm 1.1$ & $6.7 \pm 1.1$ & .7 \\
\hline Tricuspid regurgitation & & & & .5 \\
\hline None/trace & $101(23)$ & $84(22.2)$ & $17(27.4)$ & \\
\hline Mild & $145(33)$ & $127(33.6)$ & $18(29)$ & \\
\hline Moderate & $156(35.4)$ & $132(34.9)$ & $24(38.7)$ & \\
\hline Severe & $38(8.6)$ & $35(9.3)$ & $3(4.9)$ & \\
\hline Mitral regurgitation & & & & .4 \\
\hline None/trace & $67(15)$ & $53(13.9)$ & $14(21.5)$ & \\
\hline Mild & $125(28)$ & $107(28)$ & $18(27.7)$ & \\
\hline Moderate & $175(39.1)$ & $151(39.5)$ & $24(36.9)$ & \\
\hline Severe & $80(17.9)$ & $71(18.6)$ & $9(13.9)$ & \\
\hline Aortic regurgitation & & & & .4 \\
\hline None/trace & 329 (79.7) & $280(78.7)$ & $49(86)$ & \\
\hline Mild & $62(15)$ & $58(16.2)$ & $4(7)$ & \\
\hline Moderate & $15(3.6)$ & $12(3.4)$ & $3(5.3)$ & \\
\hline Severe & $2(0.5)$ & $2(0.6)$ & 0 & \\
\hline Not recorded & $5(1.2)$ & $4(1.1)$ & $1(1.7)$ & \\
\hline Right ventricular ejection fraction & & & & .2 \\
\hline Normal & $111(25.8)$ & $100(27)$ & $11(18.3)$ & \\
\hline Depressed & $319(74.2)$ & $270(73)$ & $49(81.7)$ & \\
\hline \multicolumn{5}{|l|}{ Right heart catheterization } \\
\hline Cardiac index & $1.9 \pm 0.6$ & $1.9 \pm 0.6$ & $1.9 \pm 0.6$ & .7 \\
\hline Central venous pressure, $\mathrm{mm} \mathrm{Hg}$ (mean) & $12.1 \pm 7.6$ & $12.3 \pm 7.7$ & $10.9 \pm 6.6$ & .3 \\
\hline Right ventricular systolic pressure, $\mathrm{mm} \mathrm{Hg}$ (mean) & $49.5 \pm 15.9$ & $49.3 \pm 15.1$ & $50.2 \pm 19.9$ & 1.0 \\
\hline Pulmonary arterial pressure, $\mathrm{mm} \mathrm{Hg}$ (mean) & $35.8 \pm 11.3$ & $35.7 \pm 11.2$ & $36.9 \pm 11.5$ & .4 \\
\hline Pulmonary capillary wedge pressure, $\mathrm{mm} \mathrm{Hg}$ & $25 \pm 10$ & $24.8 \pm 10.1$ & $26.1 \pm 10.1$ & .3 \\
\hline Pulmonary vascular resistance, Wood units \pm SD & $3.6 \pm 2.7$ & $3.6 \pm 2.8$ & $3.5 \pm 2.2$ & .8 \\
\hline \multicolumn{5}{|l|}{ Temporary mechanical circulatory support, n (\%) } \\
\hline Intra-aortic balloon pump & $208(44.4)$ & $187(46.4)$ & $21(31.8)$ & .04 \\
\hline Tandem heart & $59(12.6)$ & $56(13.9)$ & $3(4.5)$ & .05 \\
\hline Extracorporeal membrane oxygenation & $3(0.6)$ & $3(0.75)$ & 0 & 1.0 \\
\hline Impella & $16(3.4)$ & $15(3.7)$ & $1(1.5)$ & 6 \\
\hline \multicolumn{5}{|l|}{ Intravenous drugs, $\mathrm{n}(\%)$} \\
\hline Inotropes & $402(85.7)$ & $344(85.4)$ & $58(87.9)$ & .7 \\
\hline Vasopressors & $71(15.1)$ & $65(16.1)$ & $6(9.1)$ & .2 \\
\hline INTERMACS profile, $\mathrm{n}(\%)$ & & & & .005 \\
\hline Profile 1 (crash and burn) & $83(18.4)$ & $80(20.7)$ & $3(4.7)$ & \\
\hline Profile 2 (sliding on inotropes) & $167(37)$ & $144(37.2)$ & $23(35.9)$ & \\
\hline Profile 3 (dependent stability) & $149(33)$ & $118(30.5)$ & $31(48.4)$ & \\
\hline
\end{tabular}


TABLE 1. Continued

\begin{tabular}{|c|c|c|c|c|}
\hline & Total $(n=469)$ & Nonexchange $(n=403)$ & Exchange $(n=66)$ & $P$ value \\
\hline Profile 4 (resting symptoms) & $52(11.6)$ & $45(11.6)$ & $7(10.9)$ & \\
\hline \multicolumn{5}{|l|}{ Intraoperative variables, $\mathrm{n}(\%)$} \\
\hline Previous sternotomy & $165(35.3)$ & $147(36.7)$ & $18(27.3)$ & .2 \\
\hline Surgical approach & & & & 1.0 \\
\hline Median sternotomy & $401(85.5)$ & $344(85.4)$ & $57(86.3)$ & \\
\hline Nonsternotomy & $68(14.5)$ & $59(14.4)$ & $9(13.7)$ & \\
\hline Concomitant cardiovascular procedures & $181(38.7)$ & $158(39.3)$ & $23(34.8)$ & 6 \\
\hline Cardiopulmonary bypass use & & & & .8 \\
\hline On-pump & $426(91)$ & $365(90.8)$ & $61(92.4)$ & \\
\hline Off-pump & $42(9)$ & $37(9.2)$ & $5(7.6)$ & \\
\hline Cardiopulmonary bypass time, minutes $\pm \mathrm{SD}$ & $88.4 \pm 51.3$ & $88.7 \pm 52.1$ & $86.6 \pm 46.5$ & .8 \\
\hline Delayed closure & $218(47.1)$ & $189(47.5)$ & $29(44.6)$ & .7 \\
\hline Right ventricular assist device & $18(3.9)$ & $18(4.5)$ & 0 & .2 \\
\hline 30-d mortality, n (\%) & $55(12)$ & $52(13)$ & $3(5)$ & .08 \\
\hline \multicolumn{5}{|l|}{ Late outcomes, $\mathrm{n}(\%)$} \\
\hline Death & 210 & $168(42)$ & $42(64)$ & .001 \\
\hline Transplant & 117 & $106(91)$ & $11(9)$ & .1 \\
\hline Explanted device & 20 & $17(85)$ & $3(15)$ & 1.0 \\
\hline$\underline{\text { Survival (VAD to last follow-up), y } \pm \mathrm{SD} \text { (range) }}$ & $2.1 \pm 2.4(0-13.3)$ & $2.0 \pm 2.4(0-13.3)$ & $2.4 \pm 2.0(0.02-9.2)$ & .2 \\
\hline
\end{tabular}

exchange approaches were left subcostal $(52 \%)$, resternotomy $(40 \%)$, or left thoracotomy $(8 \%)$.

\section{Survival Analysis}

Figure 1 shows a Kaplan-Meier analysis of the overall outcomes between exchanged and nonexchanged patients. Figure 1, $A$ and $B$, shows the overall and event-free survival, respectively, after primary VAD implant (to the date of last follow-up). Overall survival and event-free survival were no different up to 4 years.

Figure 1, $C$ and $D$, shows the overall and event-free survival, respectively, during VAD support (time of primary VAD implant to date of death, explant, transplant, or last follow-up with ongoing support). Overall survival during
VAD support was no different up to 4 years. Event-free survival during VAD support was greater in the exchange group by 4 years.

Figure 2 illustrates overall survival by exchange indication. Although the results of the infection and other categories come from small samples, which preclude meaningful conclusions, the hemolysis and/or suspected thrombosis cohort showed a 2-year survival of $50 \%$; this is comparable with survival in the general CF-VAD population.

\section{Multivariable Analysis}

Multivariable regression analysis with VAD exchange as the outcome showed previous cerebrovascular events

TABLE 2. Descriptive characteristics of the exchange population

\begin{tabular}{|c|c|c|c|}
\hline & First exchange $(n=66)$ & Two or more exchanges $(n=11)$ & Total $(n=77)$ \\
\hline \multicolumn{4}{|l|}{ Device type, n (\%) } \\
\hline Jarvik 2000 & $9(13.7)$ & $0(0)$ & $9(11.7)$ \\
\hline HeartMate II & $49(74.2)$ & $9(82)$ & $58(75.3)$ \\
\hline HeartWare HVAD & $8(12.1)$ & $2(18)$ & $10(13)$ \\
\hline \multicolumn{4}{|l|}{ Indication for exchange, $\mathrm{n}(\%)$} \\
\hline Thrombosis/hemolysis & $44(66.7)$ & $5(45.5)$ & $49(63.6)$ \\
\hline Infection & $7(10.6)$ & $2(18.2)$ & $9(11.7)$ \\
\hline Other & $15(22.7)$ & $4(36.3)$ & $19(24.7)$ \\
\hline Mean time to exchange, $\mathrm{d} \pm \mathrm{SD}$ (range) & $339 \pm 390(1-1652)$ & $525 \pm 394(9-1259)$ & $375 \pm 400(1-1652)$ \\
\hline \multicolumn{4}{|l|}{ Surgical approach, n (\%) } \\
\hline Left subcostal & $36(54.5)$ & $4(36.4)$ & $40(51.9)$ \\
\hline Resternotomy & $25(37.9)$ & $6(54.5)$ & $31(40.3)$ \\
\hline Left thoracotomy & $5(7.6)$ & $1(9.1)$ & $6(7.8)$ \\
\hline
\end{tabular}

Continuous data are shown as means \pm standard deviation and categorical data as numbers (\%). SD, Standard deviation. 

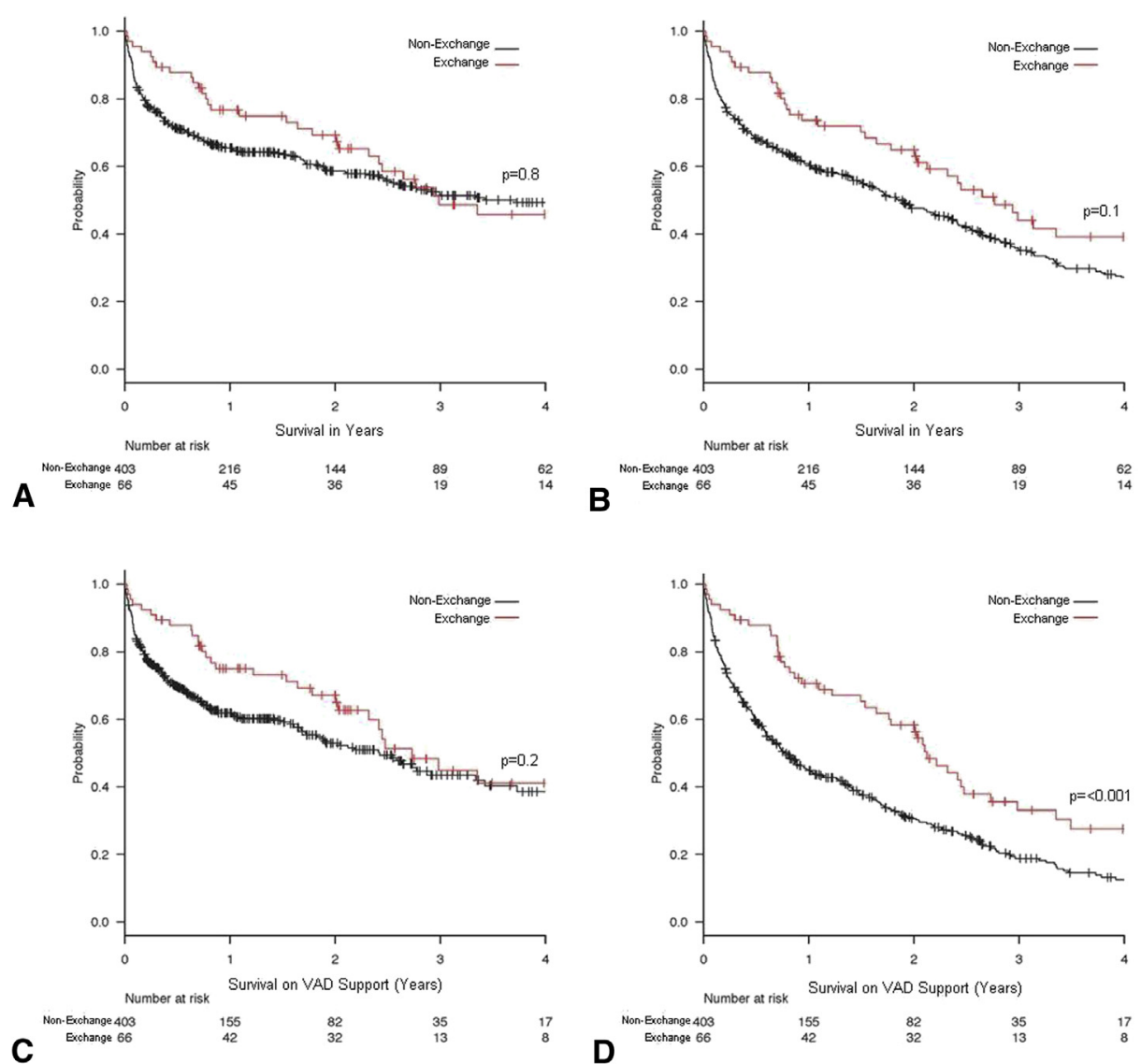

FIGURE 1. Kaplan-Meier analysis of outcomes between patients in whom a VAD was exchanged and those with no exchange. A, Survival after VAD implant (to most recent follow-up). B, Freedom from explant, transplant, or death after VAD implant (to most recent follow-up). C, Survival on VAD support. D, Freedom from explant, transplant, or death on VAD support. VAD, Ventricular assist device.

(odds ratio [OR], 4.8; 95\% confidence interval [CI], 2.2-10.2; $P<.001)$ and temporary preoperative MCS (Impella, Tandem Heart, intra-aortic balloon pump, and/or ECMO) (OR, 0.2; 95\% CI, 0.1-0.6; $P=.001)$ to be the only significant, independent predictors of survival (Table 3).

When overall survival was examined as the outcome, the impact of VAD exchange was significant (OR, 2.3; 95\% CI, $1.3-4.0 ; P=.005)$. When freedom from an event (transplant, explant, or death) while on VAD support was the outcome, VAD exchange was not significant.

\section{DISCUSSION}

The use of CF-VADs has dramatically increased in recent years. ${ }^{5}$ As more patients are supported with these devices, a natural increase in the incidence of adverse events is expected and must be effectively managed. Although the durability of MCS devices has improved in the current era, ${ }^{10}$ adverse events such as infection, ${ }^{14,25,26}$ hemolysis, ${ }^{12,27}$ thrombosis, ${ }^{28,29}$ driveline injury, ${ }^{15,23}$ and pump failure are still prevalent. In appropriately selected patients, these events can be effectively managed through primary VAD exchange. ${ }^{17,18,20,22,30,31}$

In the present study, we report the largest single-center series of CF-VAD implants to date. Our experience with axial- and centrifugal-flow devices has included the Jarvik 2000, the HeartMate II, the HeartWare HVAD, the DuraHeart, and the MicroMed DeBakey assist devices. We conducted a retrospective analysis of the data of all patients receiving CF-VAD therapy, and, after excluding those who had received a pulsatile VAD at any time in their clinical course, we identified 469 patients who are the focus of this analysis.

Univariate comparison of the data of the 66 patients who required an exchange with the data of the 403 patients who did not revealed few differences between the 2 groups. Preoperative baseline factors, including age, gender, race, indications for device implant, cause of heart failure, body mass index, and body surface area, were similar in both groups. The presence of comorbidities, including diabetes, hypertension, pulmonary disease, chronic kidney disease, hematologic disorders, 


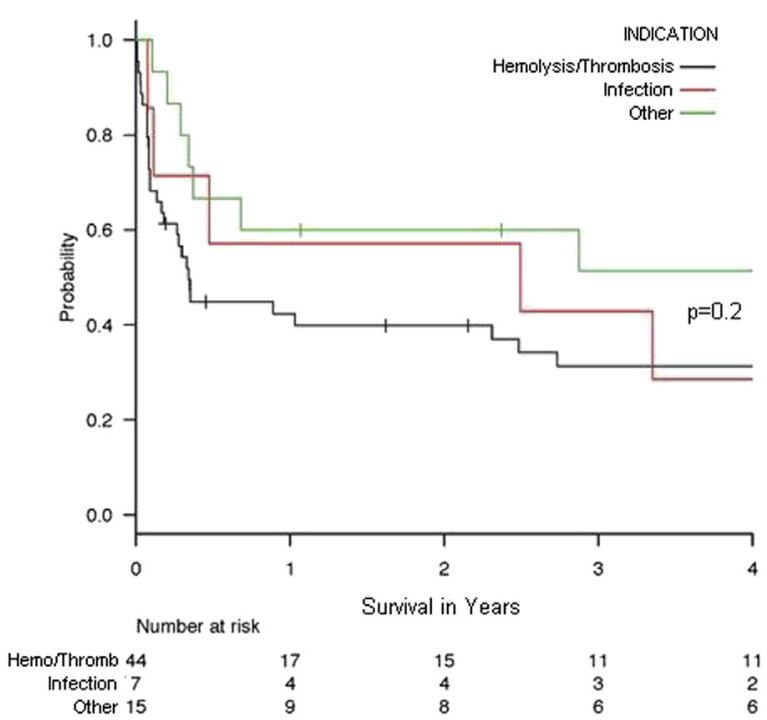

FIGURE 2. Survival (primary implant to most recent follow-up) by exchange indication.

arrhythmias, and tobacco use, was also similar. Analysis of preoperative laboratory data and echocardiographic and right heart catheterization measurements showed little to no statistically significant differences among these variables between groups. Other variables, such as the use of preoperative vasopressor and inotropic drugs and cardiopulmonary bypass (CPB), as well as CPB time, surgical approach, redo sternotomy, delayed sternal closure and emergency right VAD deployment, were all similar between groups.

Univariate analysis showed that the differences in platelet count and albumin levels between the exchange and nonexchange groups were statistically significant. Increased platelet counts in the exchange group may indicate some degree of hypercoagulability, which may possibly lead to thrombosis and the need for device

TABLE 3. Multivariable logistic regression showing significant independent predictors of exchange and survival

\begin{tabular}{llll}
\hline & \multicolumn{3}{c}{$\mathbf{9 5 \%}$} \\
& $\begin{array}{c}\text { Odds } \\
\text { ratio }\end{array}$ & $\begin{array}{c}\text { Confidence } \\
\text { interval }\end{array}$ & $\boldsymbol{P}$ value \\
\hline $\begin{array}{l}\text { Predictors of exchange } \\
\quad \text { Previous cerebrovascular event }\end{array}$ & 4.8 & $2.2-10.2$ & $<.001$ \\
$\quad \begin{array}{l}\text { Preoperative mechanical circulatory } \\
\quad \text { support }\end{array}$ & 0.2 & $0.1-0.6$ & .001 \\
$\quad \begin{array}{l}\text { Predictors of overall survival } \\
\quad \text { Exchange }\end{array}$ & & & \\
$\quad \begin{array}{l}\text { Predictors of survival while on VAD } \\
\quad \text { support }\end{array}$ & 2.3 & $1.3-4.0$ & .005 \\
$\quad$ Exchange & & & \\
\hline$V A D$, Ventricular assist device. & 1.0 & $0.4-2.1$ & .9 \\
\hline
\end{tabular}

exchange. Rossi and colleagues ${ }^{32}$ evaluated the ideal use of antiplatelet therapy in a best-practices literature review. Their report concluded that all patients with an axial-flow VAD should be on aspirin therapy alone or in combination with clopidogrel, in addition to warfarin. Our findings support that further preoperative hematologic evaluation in patients who are candidates for CF-VAD therapy may be warranted. In particular, evaluations assessing the patients' preoperative platelet functionality and responsiveness to antiplatelet therapy postoperatively may provide important insights into the risk of the patients experiencing hemolysis and/or suspected thrombosis during the period of device support.

The exchange group experienced longer durations of durable VAD support. There was a trend toward increased 30day mortality in the nonexchange group, which may have played a contributing factor. Although the value did not reach statistical significance, the proportion of patients on destination therapy was also greater in the exchange group. It can be assumed that fewer exchange patients were transplant candidates, thus lacking the option for urgent status $1 \mathrm{~A}$ listing and heart transplantation.

In a competing outcomes analysis (Figure E1), we demonstrate the overall outcomes for each patient. With the superimposed exchange curve, a nearly linear increase in the rate of exchange over time can be appreciated. The longer a patient has a pump, the more likely they are to require exchange. The patients on destination therapy are more likely to have a longer duration of support, as we have shown in our study. This puts them at a higher risk for exchange. Whereas bridge to transplant patients can be listed urgently as status $1 \mathrm{~A}$ and are more likely to undergo transplantation, patients on destination therapy do not have this option. Therefore, in the setting of complications, exchange is often the best course of action. Our data show that exchange may be performed safely and is effective in extending the duration of support in patients who experience complications.

Patients in the exchange group had higher rates of preoperative cerebrovascular events and lower rates of preoperative renal replacement therapy. Fewer exchange patients had a preoperative INTERMACS profile classification of 1 or required the use of temporary MCS devices, such as an intra-aortic balloon pump or percutaneous left VAD support. In our multivariable regression analysis for predictors of exchange, only 2 factors remained significant: the use of temporary MCS devices was negatively correlated and preoperative cerebrovascular event was strongly correlated with the need for CF-VAD exchange. Patients who required temporary MCS devices, including intra-aortic balloon pumps, ECMO, and the Impella and Tandem Heart percutaneous ventricular assist systems, were likely sicker and may not have survived long enough after implantation to have the need for CF-VAD exchange. 
The single positive predictor of CF-VAD exchange on multivariable regression was a preoperative cerebrovascular event, such as a transient ischemic attack or a cerebrovascular accident. This finding may be related to a potential hypercoaguable status in patients with a previous thromboembolic event. Alternatively, this finding may be related to a potentially poorer postoperative functional status, which has been shown to be associated with perioperative adverse outcomes in other forms of cardiac surgery. ${ }^{33}$ Thrombosis, infection, driveline injury, and other potential factors for pump exchange could all be correlated with functional limitations after a cerebrovascular event. Our findings have resulted in the routine workup for all potential patients for VAD implantation with a history of a preoperative cerebrovascular accident to be modified to include a functionality assessment, as well as a preoperative hematology consultation investigating potential inherited or acquired hypercoaguable states.

A closer analysis of the group of patients who required a pump exchange is summarized in Table 2. Our initial clinical experience with the Jarvik 2000 was described previously. ${ }^{34}$ The HeartMate II and the HVAD are the only approved CF-VADs in the United States at the time of this study. The indications for device exchange were hemolysis and/or thrombosis, infection, and other. In our study, we did not differentiate pump thrombosis from hemolysis because both are related events with multifactorial causes, ${ }^{35}$ which may be due to patient, pump, technical, or clinical management factors. The events grouped into the other category were driveline trauma, inlet malposition, pump failure of unknown cause, attempted suicide, and severe pain. Ota and colleagues ${ }^{18}$ recently reported similar results (19 of 30 devices [63\%] were exchanged because of hemolysis or thrombosis), which are proportionally identical to our own results. HeartMate II registry data showed that 7 of 70 patients underwent pump exchange because of infection $(8.9 \%)$, a result that is not greatly dissimilar from our own $(11.7 \%) .{ }^{17}$

Techniques described for exchanges have been reported previously by our own and other groups..$^{19,22,24}$ Nonsternotomy approaches included left subcostal incision and left anterior thoracotomy. The latter approach was used solely in patients implanted with a Jarvik 2000.

Our analysis showed that the overall survival of the exchange group was not significantly different from that of the nonexchange group (Figure $1, A ; P=.77$ ). Similarly, Kaplan-Meier analysis of the overall freedom from event (transplant, explant, or death) showed no difference between groups (Figure $1, B ; P=.11$ ). When KaplanMeier analysis was repeated for VAD-supported survival, with follow-up censored by date of transplant, explant, or death, again there was no statistically significant difference between exchange and nonexchange groups
(Figure $1, C ; P=.21$ ). On the other hand, the KaplanMeier analysis of freedom from event during VAD support showed a statistically significant increase in the event rate in the exchange group. There were more patients on destination therapy in the exchange cohort; likely more transplants and/or explants occurred in the nonexchange group.

\section{Limitations}

This study is limited by the retrospective nature of the data review. Furthermore, it presents the results obtained in a single center, which may not be representative of what is observed in other centers. Postoperative information including patient and device-related management factors and adverse event data were not available for all patients. However, this report is timely and relevant given the large sample size, multiple CF-VAD types with significant periods of follow-up, and the exchange incidence reported from a contemporary, high-volume center demonstrating good long-term outcomes in patients who require VAD exchange. Future multicenter prospective studies are warranted to better understand the predictors and natural history of CF-VAD exchanges.

\section{CONCLUSIONS}

In our large single-center experience with CF-VAD implants, preoperative variables including patient demographics, comorbidities, laboratory results, echocardiographic data, invasive catheterization, and operative data had little predictive power for CF-VAD exchange. The presence of cerebrovascular events before CF-VAD support did, however, have a strong correlation with the ultimate need for exchange. The decision for CF-VAD exchange should be considered for all patients who experience adverse events that can be managed appropriately by pump replacement. Exchange and nonexchange groups had similar overall survival and freedom from death while on support. Judicious and expeditious pump exchange is recommended in select patients.

The authors would like to acknowledge Dr Ana Rodriguez for editorial services, as well as David Antoun, Rohan M. Shah, Ryan W. Fairchild, and Kelly Handy for their assistance with the data collection for this manuscript.

\section{References}

1. Farrar DJ, Holman WR, McBride LR, Kormos RL, Icenogle TB, Hendry PJ, et al. Long-term follow-up of Thoratec ventricular assist device bridge-to-recovery patients successfully removed from support after recovery of ventricular function. $J$ Heart Lung Transplant. 2002;21:516-21.

2. Frazier $\mathrm{OH}$, Myers TJ. Left ventricular assist system as a bridge to myocardial recovery. Ann Thorac Surg. 1999;68:734-41.

3. Aaronson KD, Slaughter MS, Miller LW, McGee EC, Cotts WG, Acker MA, et al. Use of an intrapericardial, continuous-flow, centrifugal pump in patients awaiting heart transplantation. Circulation. 2012;125:3191-200. 
4. Birks EJ, George RS, Hedger M, Bahrami T, Wilton P, Bowles CT, et al. Reversal of severe heart failure with a continuous-flow left ventricular assist device and pharmacological therapy: a prospective study. Circulation. 2011; 123:381-90.

5. Kirklin JK, Naftel DC, Kormos RL, Stevenson LW, Pagani FD, Miller MA, et al. Fifth INTERMACS annual report: risk factor analysis from more than 6,000 mechanical circulatory support patients. J Heart Lung Transplant. 2013;32:141-56

6. Pagani FD, Miller LW, Russell SD, Aaronson KD, John R, Boyle AJ, et al. Extended mechanical circulatory support with a continuous-flow rotary left ventricular assist device. J Am Coll Cardiol. 2009;54:312-21.

7. Miller LW, Pagani FD, Russell SD, John R, Boyle AJ, Aaronson KD, et al. Use of a continuous-flow device in patients awaiting heart transplantation. $N$ Engl $J$ Med. 2007;357:885-96.

8. Park SJ, Milano CA, Tatooles AJ, Rogers JG, Adamson RM, Steidley DE, et al. Outcomes in advanced heart failure patients with left ventricular assist devices for destination therapy. Circ Heart Fail. 2012;5:241-8.

9. Rose EA, Gelijns AC, Moskowitz AJ, Heitjan DF, Stevenson LW, Dembitsky W, et al. Long-term use of a left ventricular assist device for end-stage heart failure. N Engl J Med. 2001;345:1435-43.

10. Holman WL, Naftel DC, Eckert CE, Kormos RL, Goldstein DJ, Kirklin JK. Durability of left ventricular assist devices: Interagency Registry for Mechanically Assisted Circulatory Support (INTERMACS) 2006 to 2011. J Thorac Cardiovasc Surg. 2013;146:437-41.e1.

11. Slaughter MS, Rogers JG, Milano CA, Russell SD, Conte JV, Feldman D, et al. Advanced heart failure treated with continuous-flow left ventricular assist device. N Engl J Med. 2009;361:2241-51.

12. Cowger JA, Romano MA, Shah P, Shah N, Mehta V, Haft JW, et al. Hemolysis: a harbinger of adverse outcome after left ventricular assist device implant. J Heart Lung Transplant. 2014;33:35-43.

13. Boyle AJ, Jorde UP, Sun B, Park SJ, Milano CA, Frazier OH, et al. Pre-operative risk factors of bleeding and stroke during left ventricular assist device support: an analysis of more than 900 HeartMate II outpatients. J Am Coll Cardiol. 2014;63: 880-8.

14. Zierer A, Melby SJ, Voeller RK, Guthrie TJ, Ewald GA, Shelton K, et al. Lateonset driveline infections: the Achilles' heel of prolonged left ventricular assist device support. Ann Thorac Surg. 2007;84:515-20.

15. Kalavrouziotis D, Tong MZ, Starling RC, Massiello A, Soltesz E, Smedira NG, et al. Percutaneous lead dysfunction in the HeartMate II left ventricular assist device. Ann Thorac Surg. 2014;97:1373-8.

16. Abicht T, Gordon R, Meehan K, Stosor V, McCarthy P, McGee E Jr. Complex HeartMate II infection treated with pump exchange to HeartWare HVAD. ASAIO J. 2013;59:188-92.

17. Moazami N, Milano CA, John R, Sun B, Adamson RM, Pagani FD, et al. Pump replacement for left ventricular assist device failure can be done safely and is associated with low mortality. Ann Thorac Surg. 2013;95: 500-5.

18. Ota T, Yerebakan H, Akashi H, Takayama H, Uriel N, Colombo PC, et al. Continuous-flow left ventricular assist device exchange: clinical outcomes. J Heart Lung Transplant. 2014;33:65-70.

19. Sajjad M, Butt T, Oezalp F, Siddique A, Wrightson N, Crawford D, et al. An alternative approach to explantation and exchange of the HeartWare left ventricular assist device. Eur J Cardiothorac Surg. 2013;43:1247-50.

20. Stulak JM, Cowger J, Haft JW, Romano MA, Aaronson KD, Pagani FD. Device exchange after primary left ventricular assist device implantation: indications and outcomes. Ann Thorac Surg. 2013;95:1262-7; discussion 1267-8.

21. Adamson RM, Dembitsky WP, Baradarian S, Chammas J, Jaski B, Hoagland P, et al. HeartMate left ventricular assist system exchange: results and technical considerations. ASAIO J. 2009;55:598-601.

22. Cohn WE, Mallidi HR, Frazier OH. Safe, effective off-pump sternal sparing approach for HeartMate II exchange. Ann Thorac Surg. 2013; 96:2259-61.

23. Jafar M, Gregoric ID, Radovancevic R, Cohn WE, McGuire N, Frazier OH. Urgent exchange of a HeartMate II left ventricular assist device after percutaneous lead fracture. ASAIO J. 2009:55:523-4.

24. Gregoric ID. Exchange techniques for implantable ventricular assist devices. ASAIO J. 2008:54:14-9.

25. Goldstein DJ, Naftel D, Holman W, Bellumkonda L, Pamboukian SV, Pagani FD, et al. Continuous-flow devices and percutaneous site infections: clinical outcomes. J Heart Lung Transplant. 2012;31:1151-7.
26. Nienaber JJ, Kusne S, Riaz T, Walker RC, Baddour LM, Wright AJ, et al. Clinical manifestations and management of left ventricular assist device-associated infections. Clin Infect Dis. 2013;57:1438-48.

27. Ravichandran AK, Parker J, Novak E, Joseph SM, Schilling JD, Ewald GA, et al Hemolysis in left ventricular assist device: a retrospective analysis of outcomes. $J$ Heart Lung Transplant. 2014;33:44-50.

28. Kirklin JK, Naftel DC, Kormos RL, Pagani FD, Myers SL, Stevenson LW, et al. Interagency Registry for Mechanically Assisted Circulatory Support (INTERMACS) analysis of pump thrombosis in the HeartMate II left ventricular assis device. J Heart Lung Transplant. 2014;33:12-22.

29. Starling RC, Moazami N, Silvestry SC, Ewald G, Rogers JG, Milano CA, et al. Unexpected abrupt increase in left ventricular assist device thrombosis. N Engl J Med. 2014;370:33-40.

30. Potapov EV, Kaufmann F, Stepanenko A, Hening E, Vierecke J, Löw A, et al Pump exchange for cable damage in patients supported with HeartMate II left ventricular assist device. ASAIO J. 2012;58:578-82.

31. Tang GH, Kim MC, Pinney SP, Anyanwu AC. Failed repeated thrombolysis requiring left ventricular assist device pump exchange. Catheter Cardiovasc Interv. 2013;81:1072-4.

32. Rossi M, Serraino GF, Jiritano F, Renzulli A. What is the optimal anticoagulation in patients with a left ventricular assist device? Interact Cardiovasc Thorac Surg. 2012;15:733-40.

33. Mayer C, Ergina P, Morin JF, Gold S. Self-reported functional status as a predictor of coronary artery bypass graft surgery outcome in elderly patients. Can J Cardiol. 2003;19:140-4.

34. Frazier OH, Myers TJ, Gregoric ID, Khan T, Delgado R, Croitoru M, et al. Initial clinical experience with the Jarvik 2000 implantable axial-flow left ventricular assist system. Circulation. 2002;105:2855-60.

35. Uriel N, Han J, Morrison KA, Nahumi N, Yuzefpolskaya M, Garan AR, et al. Device thrombosis in HeartMate II continuous-flow left ventricula assist devices: a multifactorial phenomenon. J Heart Lung Transplant. 2014;33:51-9.

\section{Discussion}

Comoderator. Our next paper is entitled "Continuous-flow ventricular assist device exchange is safe and effective in prolonging support time in patients with end-stage heart failure," and this will be given by Dr Anand.

Dr Anand. Good morning, thank you to the association for the opportunity to present our work. Myself and my coauthors have no relevant disclosures. Continuous-flow ventricular assist devices have greatly improved our ability to care for patients with endstage heart disease. Compared with the previous generation of pulsatile devices, continuous-flow devices have demonstrated improved durability, improved survival, better long-term outcomes, and fewer adverse events. Contemporary continuous flow devices used around the world include the axial-flow Heart Mate II and Jarvik 2000 pumps as well as the centrifugal-flow HeartWare HVAD. Overall, more than 20,000 patients are now being supported around the world and this number is increasing rapidly. The figure to the right from a recent report of the INTERMACS database shows that in the last few years there has been a nearly exponential increase in the number of patients being implanted. However, complications of continuous-flow VAD therapy remain common. Certain complications such as hemolysis, thrombosis, infection, driveline trauma, and mechanical failure can sometimes be appropriately managed through pump exchange. We asked the questions: at the time of primary continuous-flow ventricular assist device implant, are there baseline factors that predict the need for future pump exchange? What is the overall incidence of continuous-flow VAD exchange? What are the outcomes after the exchange? 
Our objective was to examine our center's experience with continuous-flow VAD exchanges with the primary aim to determine any significant independent predictors for exchange at the time of initial implant. Secondary aims included the evaluation of survival and event-free survival with event being defined as death, transplant, or explant. We performed a retrospective chart review of our center's experience with continuous-flow VAD therapy from 1999 to 2013. We identified all patients who received a primary continuous-flow VAD implant and excluded patients who had received a pulsatile VAD at any point during their clinical course. We identified all patients who experienced an exchange, and summarized demographics, indications, echocardiographic and invasive hemodynamic data, operative, perioperative, and late clinical outcomes. We used univariate analysis to compare the nonexchanged and the exchanged cohorts as well as multivariable regression analysis to identify any significant predictors for exchange at the time of initial implant. Time-to-event and survival analyses were performed using the Kaplan-Meier method.

This figure demonstrates our overall experience with continuous-flow VAD implants and exchanges. The top curve shows the total number of implants over time and the bottom curve in red shows the number of exchanges over time. A continuousflow VAD was implanted in 469 patients at our institution: 327 HeartMate II, 74 Jarvik 2000, 65 Heart Ware HVAD, 2 DuraHeart and 1 MicroMed-DeBakey at the initial implantation. Sixty-six patients required an initial exchange. Nine patients went on to require a second exchange and 2 patients went on to require a third exchange. The pumps implanted initially are shown on the left, with the pumps that they were replaced with shown on the right. Overall, the total number of exchanged VADs were 59 HeartMate II, 10 Jarvik 2000, and 8 HeartWare HVAD. To look at this a little more closely, for the HeartMate II, we had 59 exchanges with 379 implants spanning 466 patient-years; for the Jarvik 2000, there were 10 exchanges, 84 implants, and 35 patient-years of support; and for the HeartWare HVAD, we had 15 exchanges, 80 implants spanning more than 91 patient-years of support. This translated to a 0.13 event per patient-year exchange rate for the HeartMate II, 0.29 event per patient-year exchange rate for the Jarvik 2000, and 0.16 event per patient-year exchange rate for the HeartWare HVAD.

The competing outcomes chart (Figure E1) represents the fate of the VADs over time. You can see that the orange curve shows the patient survival, and this correlates inversely with the green curve, which shows death. The light blue curve represents the patients who were alive on support and this correlates inversely with the dark blue and the red curves, which represent patients who were implanted or explanted for recovery. The purple curve demonstrates our exchanges over time, and what you can see is that the longer a patient has a VAD, the greater the risk for exchange.

Looking more closely at our exchange cohort, of all patients who were exchanged, $64 \%$ had indications of hemolysis or suspected thrombosis; $12 \%$ had infections; and $25 \%$ were classified as other, which included driveline trauma, inlet malposition, and 1 patient who attempted suicide. Surgical approaches included resternotomy in $40 \%$ and a nonsternotomy approach in the remainder. We used univariate analysis to compare our exchange and nonexchange cohorts. Overall, we found that the groups were fairly similar. There was a significant difference between stroke and transient ischemic attack (TIA) in patients who had undergone exchange. There was a greater rate of preoperative cerebrovascular events. Also patients who were in the nonexchanged group had higher rates of renal replacement therapy before the implant. When looking at the laboratory results, patients who had undergone exchange had a higher platelet count and higher levels of albumin. Echocardiographic data were largely similar between both groups. The right heart catheterization data were similar between both groups. In our nonexchanged group, we found that more patients had required preoperative temporary mechanical circulatory support including intra-aortic balloon pump and tandem heart. A greater number of nonexchanged patients were also in the INTERMACS profile I category, which is crash and burn, meaning a sicker cohort. Intraoperative variables were evaluated. Surgical approach, concomitant procedures, the use of cardiopulmonary bypass and pump time, delayed sternal closure, and emergency right VAD implantation were similar between both groups. There was a trend toward increased 30-day mortality in the nonexchanged cohort. Late outcomes and survival were similar in both groups.

In our multivariable regression model, we identified preoperative cerebrovascular events, including stroke and TIA, as significant predictors for pump exchange. The use of preoperative mechanical circulatory support was negatively associated with exchange, which makes sense because those patients probably did not survive to the point of needing a pump exchange. When we repeated our multivariable regression to evaluate for overall survival as the outcome, we found that exchange was a significant predictor for overall survival. In our Kaplan-Meier analyses, we evaluated survival after VAD implant, which was defined as implant to the date of last follow-up, as well as freedom from event, with event being defined as transplant, explant, or death. We found no differences between the group that required pump exchange and those that did not. We repeated this analysis for patients to evaluate survival during VAD support as well as freedom from event during VAD support. There was no difference between the groups and their survival while on support, but there was a greater freedom from event in the exchange group. We repeated the evaluation for survival by indication and found that in patients who were exchanged for hemolysis or thrombosis, infection, or other, there was no significant difference between long-term survival in these groups.

In summary, we report the largest single-center exchange series to date and found a $14 \%$ overall incidence of VAD exchanges with exchange rates of 0.13 event per patient-year for the HeartMate II, 0.29 event per patient-year for the Jarvik 2000, and 0.16 event per patient-year for the HeartWare HVAD. Our nonexchange and exchange groups had similar characteristics at baseline. The nonexchange group did seem to have a higher early mortality and increased risk for poor outcome. On multivariable regression analysis, cerebrovascular events were associated with greater need for exchange.

This study does have limitations. It is a single-center retrospective review with significant bias in the sense that 
postoperative patient management factors including pump speed, revolutions per minute, patient anticoagulation, internationalized normalized ratio (INR), and overall blood pressure control parameters were not incorporated into this analysis. Similarly, adverse events were not incorporated. However, the purpose of this study was to evaluate the risk for exchange at the time of initial pump implant. And based on that data, we were able to identify preoperative stroke or TIA as a significant predictor. We found, based on our long-term data, that pump exchange in the setting of complications can be done safely with good long-term outcomes. Therefore, we recommend expeditious and judicious pump exchange in patients with appropriate indications.

I would like to thank my mentors and my research associates and take any questions.

Comoderator. Thank you. Our discussant is Dr Mokadam.

Dr Mokadam. I would like to thank the Association for the privilege of reviewing this abstracting paper and Dr Anand for providing me the abstract and manuscript way in advance. This is great work and very important work in the world of heart failure. Pump exchange is a hot topic for us and I would like to congratulate the authors for their contribution. I have 3 comments and questions. You identify preoperative neurologic events as the only really significant risk factor for pump exchange. In your manuscript, you talk about an unidentified hypercoagulable state. What do you do now for patients who have preoperative neurologic events and how do you work them up when you are preparing for VAD implant?

Dr Anand. Thank you for the question. When patients with a previous stroke or TIA present, we are very careful in our preoperative workup to look for modifiable factors such as hypercoagulability. Using platelet function testing and thromboelastography analysis both preoperatively and postoperatively, we are careful to ensure adequate anticoagulation at all times. In addition, postoperative blood pressure management is very important in these stroke patients. Even though we have augmented the workup and management of these patients, we do not yet have the data to show the long-term outcomes. We are monitoring this very closely.

Dr Mokadam. It is interesting that you note a higher rate of exchange in the destination therapy group. Many people have speculated that it is the younger patients who are more hypercoagulable. Do you think that there is something specific to the destination therapy group other than simply time on pump that leads to a higher rate of exchange?

Dr Anand. The destination therapy group is often not eligible for a transplant in the setting of pump complications. In the bridge-to-transplant groups, we may be able to urgently list them as status IA and find them a donor heart, but this is not usually an option in the destination therapy patient group. Therefore, pump exchange is often 1 of the only routes that we can take to prolong the duration of support. And I think it is important that we are able to show good outcomes in our center.

Dr Mokadam. I think this goes back to my third question, which is probably the hardest 1 for you to answer. Your survival analysis really showed no statistical difference in the exchange versus the nonexchange group, but I think this is due to statistical bias. In your nonexchange group, there were probably patients who thrombosed who did not get exchanged; for example, the patients who got a transplant or the patients who died of presumed pump thrombosis. I think your statistical analysis may benefit from something like a time-dependent covariable analysis. And you did show your competing outcomes analysis. If you took out the patients who had presumed or confirmed pump thrombosis who did not get an exchange, would your survival curves look different?

Dr Anand. Thank you for that question. That is a very good point. We did do further analysis and I did not show this in the interest of time. I did go back and reevaluate the patients with early mortality after exchange. For patients who experienced 30-day mortality: when we removed them from the analysis, the survival curves looked the same as what we reported. In terms of the statistical analysis, the focus of this study was primarily to identify if there were any significant predictors at the time of initial implant. I mentioned in the limitations that we did not evaluate a lot of the pump management and postoperative events, but now that we have identified that there are very few preoperative events that predict pump exchange, the next phase of our study is to do exactly that. We are looking carefully at the adverse events and patient management factors to identify the effect of those factors on pump exchange. And at that time, time variant covariant analysis will be very important, and we will be doing that.

Dr Mokadam. I would like to congratulate you again. This is great work

Dr Anand. Thank you, sir.

Comoderator. Dr Cleveland.

Dr Cleveland. Good morning, Joe Cleveland from Denver. Very nicely presented work and as you pointed out already, it is a timely topic. So to delve deeper into a couple of things, 1 is a question about anticoagulation management in terms of the INR, where is this followed? So what type of protocol do you have here? I know I take it 2 to 3 standard type things. Who is following the INRs? Texas Heart or were some of these patients sent outside, done, and then came back in with subtherapeutic INRs?

Dr Anand. Our patients are followed weekly in our clinic and we have a group of heart failure cardiologists as well as hematologists who follow these patients. We keep the INR in the 2 to 3 range, and, as you know, it is inevitable at times that patients present with subtherapeutic INRs. Whether it is patient compliance, diet, and so forth, it is the reality of warfarin. We are looking more carefully at postoperative laboratory values and other factors so that we can determine what exactly contributes to the rate of thrombosis and exchange in these patients as well.

Dr Cleveland. So to follow up on that question, do your patients routinely have lactate dehydrogenase (LDH) values drawn, and are some of these exchanges driven by that? I think that is 1 of the greatest things we have been struggling with as a community. Their LDH level doubles, they seem to be fine. You admit them, put them on some other heparin and the $\mathrm{LDH}$ continues to climb. Is that a trigger in your institution to exchange them preemptively or do you wait for more 
advanced signs of hemolysis such as dark urine, and so forth, pump dysfunction?

Dr Anand. I did not show the data, but we actually did record the LDH in all the patients who presented with hemolysis or thrombosis. We did not try to separate those groups because, as you know, often the pumps may be exchanged and there is no gross clot seen at the time of surgery. But if you send the pump back to the manufacturer for analysis, they might find some thrombus in the pump. If there is blood stasis, thrombus can form even after the fact. But with regard to hemolysis, Dr Cowger and others have shown the significance of hemolysis in terms of long-term outcomes. At our institution, hemolysis alone is not the trigger for pump exchange. The patient's overall condition is definitely the trigger. And I think we are aggressive with pump exchanges when necessary. I have shown that the outcomes are good. With regard to the data on the LDHs, I believe our mean LDH for patients who underwent exchange for hemolysis was around 700 to $800 \mathrm{U} / \mathrm{L}$.

Dr Cleveland. Thank you.

Dr Anand. Thank you, sir.

Dr Shemin. Richard Shemin from Los Angeles. Very nice study. My question is, when you use the term pump exchange, are you referring to inflow and outflow components as well as the motor because there is controversy on how to do?

Dr Anand. Yes.

Dr Shemin. Also you have had multiple patients who have required more than 1 exchange and was there a relationship that only the motor was changed but not the inflow and outflow and you had to go back and do it again?

Dr Anand. That is a great question. With regard to the first part, we have used various techniques; it is a case-by-case basis, as you know. With regard to the HeartMate II, the exchange can also be done off pump with a left subcostal incision, clamping the outflow and inflow, and just replacing the pump housing; for the HeartWare HVAD, you often need cardiopulmonary bypass and likely a redo median sternotomy. So the answer to the question is that it is variable and there is ongoing work that will look more carefully at those data. And the second question ...?
Dr Shemin. In the people who had multiple exchanges.

Dr Anand. Yes sir. In our multiple exchange groups, I am going to look more carefully at those data, but overall, there was not much difference in survival as far as the technique used with the actual inlet cannula, the outflow graft, and the specific surgical factors. But I have to summarize those data. I do not have that information right now.

Dr Shemin. So right now, in your practice with the HeartMate II, when you go back for an exchange, how extensive is that exchange operation?

Dr Anand. Typically, that operation is performed via a left subcostal incision without cardiopulmonary bypass, controlling the inflow and outflow grafts with clamps, and replacing the pump itself. However, there are instances when, if it is for an infection and the infection carries all the way down to the pump body itself, we will perform a redo median sternotomy, remove the entire HeartMate II, the inlet, plus or minus the sewing ring, and place an intrapericardial HVAD. We have shown very good results with those patients because we have been able to isolate the site of infection in the abdomen away from the intrathoracic, intrapericardial HVAD. So it is variable, on a case-bycase basis.

Thank you.

Comoderator. Last question.

Dr Wozniak. Kurt Wozniak from San Francisco. I think the group from Oregon tomorrow is going to discuss Factor VII and left ventricular assist devices. I am wondering if you looked at the use of Factor VII in the use of blood in blood products around the time of initial implant; and if that had any impact on pump exchange?

Dr Anand. That is a very good point. We are currently collecting the data at our institution. I think, as many people know in terms of databases and data entry, certain things can be difficult and finding the exact numbers of intraoperative and perioperative blood products has been a challenge. I hope to report some more information on Factor VII and other coagulation products used in these VAD patients soon.

Comoderator. Thank you very much.

Dr Anand. Thank you. 


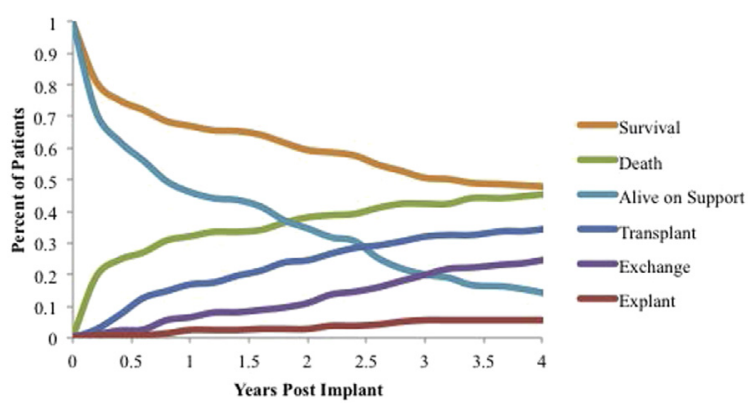

FIGURE E1. Competing outcomes analysis of patients with a continuousflow ventricular assist device (CF-VAD) with superimposed rate of exchange curve. This figure demonstrates the outcomes of all patients with CF-VAD in our study cohort. The survival curve inversely correlates with the death curve. The alive-on-support curve inversely correlates with the final event curves (transplant and explant). The exchange curve is superimposed to demonstrate the number of exchanges in this population over time. 